\title{
Philosophiques
}

\section{Pierre Du Calvet, Appel à la justice de l'état, Extraits présentés par Jean-Paul de Lagrave et Jacques G. Ruelland Éditions du Griffon d'Argile. 1986. 64 pages.}

\section{Emile Chrétien}

Volume 14, numéro 2, automne 1987

URI : https://id.erudit.org/iderudit/027023ar

DOI : https://doi.org/10.7202/027023ar

Aller au sommaire du numéro

Éditeur(s)

Société de philosophie du Québec

ISSN

0316-2923 (imprimé)

1492-1391 (numérique)

Découvrir la revue

Citer ce compte rendu

Chrétien, E. (1987). Compte rendu de [Pierre Du Calvet, Appel à la justice de l'état, Extraits présentés par Jean-Paul de Lagrave et Jacques G. Ruelland Éditions du Griffon d'Argile. 1986. 64 pages.] Philosophiques, 14(2), 437-440. https://doi.org/10.7202/027023ar d'utilisation que vous pouvez consulter en ligne.

https://apropos.erudit.org/fr/usagers/politique-dutilisation/ 
PIERRE DU CALVET, Appel à la justice de l'état, Extraits présentés par JeanPaul de Lagrave et Jacques G. Ruelland Éditions du Griffon d'Argile. 1986. 64 pages.

$$
\text { par Émile Chrétien }
$$

À l'occasion du bicentenaire de la mort tragique de Pierre du Calvet (1735-1786), ce livre a été publié pour réhabiliter ce grand défenseur des libertés individuelles et de la démocratie, auteur qui a été quelque peu délibérément oublié par les historiens officiels.

Son Appel à la Justice d'État fut publié en 1784 entre la guerre d'indépendance des États-Unis d'Amérique et la Révolution françaıse. C'est un livre qui défend les grandes idées inspiratrices de la future déclaration des 
droits de l'homme et du citoyen, un livre inspiré des philosophes des lumières du XVIII ${ }^{e}$ siècle.

L'étude historique présentée ici, comprend une biographie assez détaillée de Pierre du Calvet (13 pages), une présentation de son œuvre ( 6 pages) et une série des extraits les plus significatifs ( 45 pages).

\section{SA BIOGRAPHIE}

D'origine française et protestante, Pierre du Calvet s'installa à Montréal en 1758. Après avoir défendu la Nouvelle-France auprès du général Lévis, il demeura dans sa ville d'adoption après la conquête et devint un commerçant prospère ainsi qu'un juge de paix. Cependant ses sympathies idéologiques pour la révolution américaine l'entraînèrent en prison pour trois ans (1780-83) et lui apportèrent maints déboires financiers et personnels. Son $A p p e l$ est à la fois une protestation contre les injustices dont lui et ses amis furent victimes et un plaidoyer pour des institutions plus démocratiques pour le Canada. Ce fut un intellectuel dissident qui participa avec Fleury Mesplet et Valentin Jautard à la naissance de la Gazette Littéraire et à la fondation de l'Académie de Montréal en l'honneur de Voltaire en 1778. Il réclama par ses écrits l'introduction de lois anglaises au Canada, la liberté de la Presse, l'Habeas Corpus et un système parlementaire. Malheureusement pour lui, on était alors sous un régime d'occupation militaire. Il manifesta ouvertement ses sympathies pour le régime démocratique américain au grand dam du Gouverneur Haldimand. Il répandit au Canada catholique les idées des philosophes des lumières. Cela en était trop pour une société comme le Québec de cette époque, une société religieuse conservatrice et d'ancien régime mais ses idées furent reprises par d'autres, plus tard, les patriotes de 1837-38 et les défenseurs de l'Institut canadien. Ce fut un précurseur, incompris comme la plupart des précurseurs, mais dont la pensée nous inspire encore aujourd'hui.

\section{SON OEUVRE}

L'Appel à la Justice d'État est formé d'un recueil de lettres adressées au Roi, au Prince de Galles, au Gouverneur Général Fréderik Haldimand, au secrétaire d'État et au peuple canadien lui-même. Cette œuvre maîtresse est un plaidoyer pour la liberté, un écrit, inspiré de John Locke, contre le despotisme gouvernemental. L'auteur y réclame l'établissement d'un régime démocratique au nom des droits humains fondamentaux. L'auteur s'y présente comme victime d'un esclavage inadmissible dans une colonie britannique qui devrait jouir des libertés fondamentales. Il réclame de plus des tranformations politiques dans le sens de plus de démocratie. Ce livre permet la cristallisation des énergies des canadiens pour réclamer le retour des libertés individuelles ainsi que l'instauration d'une chambre d'assemblée et d'un gouvernement responsable. Ce qui ne fut malheureusement réalisé qu'au milieu du $\mathrm{XIX}^{\mathrm{e}}$ siècle. 
Parmi la douzaine de lettres qui forment l'ouvrage, la plus importante est celle adressée aux Canadiens (195 pages sur 328 pages). L'auteur y brosse un tableau du régime despotique et au nom de la liberté exige un gouvernement démocratique à Québec et pour ce faire une véritable chambre d'assemblée. Il écrit en effet : « à l'époque de la cession, irrévocablement signée à Fontainebleau, la colonie, en vertu d'une proclamation fut associée, de théorie royale, au corps des colonies sujettes de l'Angleterre; mais le pouvoir exécutif à Québec n'associa pas de pratique ses enfants à la jouissance des prérogatives des citoyens (...) les Canadiens furent déclarés étrangers, intrus, esclaves civils dans leur propre pays ; c'est à dire qu'on les assujettit à leur mise des impôts et des taxes de l'état mais sans le titre primitif et fondamental en vertu duquel seul un état peut être autorisé par le droit social à imposer de pareilles obligations (...)» (p. 37).

L'auteur y suggère un plan de réforme en onze points inspiré d'ailleurs du philosophe John Locke, grand théoricien de la démocratie britannique. Il écrit en effet : «La puissance législative est donc l'âme du corps politique (...). Tellement que quand le pouvoir législatif est ruiné ou dissous, la dissolution, la mort de tout le corps politique s'ensuit.» (p. 14)

Il préconise donc un pouvoir législatif découlant de la volonté du peuple et dénonce le despotisme comme le plus grand danger pour les libertés.

Partant du sort horrible qui lui avait été réservé malgré qu'il aie été un des notables les plus importants de Montréal, il demande l'aide de la métropole pour contrer la tyrannie d'un gouverneur peu respectueux des principes démocratiques.

Il proclame le droit souverain du peuple à s'opposer au régime politique existant parce que despotique. Il précise même que les conquérants ont des droits limités et que les conquis, comme les Canadiens, demeurent malgré la conquête des hommes libres. Il écrit en effet: "Quelle est donc alors la destinée nationale et civile des peuples conquis? Il faut remonter ici jusqu'à l'origine primitive des sociétés. Au sortir des mains de la nature, les hommes naissent tous égaux ; quand ils se formèrent en corps de société nationale ce fut de leur choix que, se défaisant de leur égalité naturelle, ils érigèrent une autorité générale qui ne fut légitimée que par le consentement formel et positif, comme elle l'est encore aujourd'hui par le consentement tacite et présumé de leurs descendants ; (p. 39)

Il montre l'abandon de toutes les libertés dans le contexte politique de son époque.

Sa pensée rejoint à la fois le point de vue de Voltaire et celui de d'Holbach qui a écrit : « La tyrannie est l'injustice appuyée par la force » et encore : « pour sentir le prix de la liberté, il faut savoir tout lui sacrifier. »

Je me permettrai ici de citer, en guise de conclusion à l'analyse de son auvre, ce texte encore très actuel qu'il adressa à ses concitoyens : «... c'est à vous maintenant à vous défendre vous-même. Si imitant le passé, vous êtes les 
spectateurs oisifs et insensibles des événements, eh bien! Votre province va être pour longtemps confirmée dans son esclavage jusqu'à ce que le désespoir au moins lui suscite des vengeurs (...) c'est à vous à voir s'il vous convient de vivre dans un vrai coupe-gorge où personne ne peut être un seul moment assuré de sa fortune, de sa liberté, de son honneur et de sa vie. J'ai des idées trop nobles de vos sentiments pour imaginer qu'une terrible destinée puisse jamais être de votre coût... » (p. 44)

C'est pour obtenir justice pour lui-même et pour ses concitoyens, c'est dans l'espérance d'une société future plus juste et plus démocratique, que Pierre du Calvet publia son $A p p e l$, en français et en anglais. Il entreprit des démarches judiciaires contre le gouverneur Haldimand auprès du gouvernement anglais. Malheureusement pour lui, il n'obtint jamais justice et mourut prématurément dans un naufrage. Cependant son Appel fut entendu de ses concitoyens progressistes qui aimaient la liberté et la démocratie. Même en ces jours, son $A p p e l$ a encore un sens pathétique pour ceux qui rêvent de plus de démocratie, de justice et de liberté.

La présentation par M. Jean-Paul de Lagrave et M. Jacques G. Ruelland de la vie et l'œuvre de Pierre du Calvet, suivi des extraits les plus significatifs de son cuvre, est à proprement parler remarquable. C'est avec beaucoup d'intérêt que les lecteurs s'intéressant à l'histoire intellectuelle du Québec, à l'histoire de la dissidence dans le Québec traditionnel, découvriront cette étude historique fort intéressante. C'est de plus un livre facile d'accès et à usage pédagogique très valable dans les cours d'histoire des idées philosophiques et politiques au Québec.

Département de philosophie

C.E.G.E.P. Montmorency 